\title{
Unpacking the learning on consultant-led ward rounds: Lessons from ethnography in paediatrics
}

\author{
H. Enright ${ }^{1,2,3}$ \& A. Gray ${ }^{2,3}$
}

\begin{abstract}
Introduction: Consultant-led ward round education in a busy paediatric setting is a complex process and is often ad hoc. We aimed to observe ward rounds to better understand the education opportunities available.
\end{abstract}

Methods: Drawing on Argyris and Schön's (1974) theory of action, we used an ethnographic approach to observe 30 general medical ward rounds over a 3-month period, from September to December 2016. For this study we analysed the learning opportunities and the content that is explicitly taught in relation to the domains of professional practice that we espouse to teach.

Results: There were many layers of learning potential observed in ward round practice. These included clinical learning, communication, professional skills and identity and institutional cultural context. Clinical learning was prioritised; however, other learning domains remained implicit and were often ignored.

Discussion: Our findings highlight great complexity in ward round learning and teaching. There was significant missed educational potential in the ward round environment as well as a need for a major shift in educational focus from clinical to other professional domains. Following Argyris and Schön (1974), it is necessary to examine what we espouse against our actual educational practice. This can inform a planned or structured approach to exploit the maximum potential of ward round learning and teaching.

Conclusions: Ward round education is a priority that benefits from observation, reflection and development of new models of practice. If we are not conscious of what we are teaching on rounds, and how this is occurring, we risk losing opportunities to draw on all of the learning potential available.

\footnotetext{
La Trobe University, Melbourne, Australia

University of Melbourne, Australia

Royal Children's Hospital, Melbourne, Australia
}

\section{Correspondence}

Helen Enright

La Trobe University

Bundoora, Victoria 3086

Australia

Tel: +61394795189

Email: h.enright@latrobe.edu.au 
Keywords: ward round education; medical education; paediatrics; child health; learning and teaching; clinical learning; work-based education

\section{Introduction}

Consultant ward rounds are a busy, complex process of assessing and managing the clinical daily needs of patients. Although the composition and labelling of rounds may vary in different contexts, in Australia, ward rounds often involve a team of trainee doctors and medical students visiting patients at the bedside, with the consultant overseeing management of patient care. Complex clinical knowledge, skills in decision making and diagnosis, management expertise and ability to synthesise information and prioritise care are features of ward rounds (O'Hare, 2008). In the paediatric setting, this is complicated by the additional presence of children as patients and their parents or carers who may be understandably worried, stressed and/or exhausted. Education of trainee doctors and medical students also takes place on these ward rounds. It is a multifaceted, busy environment, which often spawns an ad hoc, unsystematic environment for learning. As a consequence, there is often tension between the service provision of clinical care and the demand of good educational practice (Argyris et al., 1985; Powell et al., 2015; Stanley, 1998). This can result in the quality of learning and teaching being compromised and opportunities for education being lost (Dewhurst, 2010; Laskaratos, Parry, \& El-Mileik, 2016; Laskaratos, Wallace, et al., 2015).

Through a developmental evaluation (Patton, 2011) of learning and teaching on ward rounds, we conducted a focused ethnography of ward rounds in the general medicine department at a tertiary paediatric teaching hospital (Gray \& Enright, 2018). This included observation of rounds, consultant surveys and focus groups of junior medical staff. Our intention was to better understand how education functions in practice in the ward round context and how such education may be enhanced. We wanted to understand how ward rounds operate, what opportunities for education occur and whether teaching on rounds is underpinned by educational theory. In our initial work, we found that consultant teaching was largely ad hoc, implicit, often didactic and, understandably, played a secondary role to the service provision of patient care (Gray \& Enright, 2018). These findings have been reflected in other literature (Dewhurst, 2010; Laskaratos, Parry, \& El-Mileik, 2016; Stanley, 1998). There were many opportunities for learning but also many missed opportunities and an overemphasis on technical content at the cost of professional competencies such as communication, teamwork and advocacy.

Ward rounds are, in fact, a messy labyrinth of cognitive decision making, clinical assessments, work-focused tasks and a multiplicity of competing interactions in a unique hospital context. They have been compared to walking a tightrope (Ker et al., 2017). How do we take this reality and make it into a learning opportunity that is more focused and prioritised? How do we decide what to prioritise and teach? The aim of this paper was to undertake a deeper analysis of our existing observational data of ward rounds, with a view to articulating the "what" of educational potential on ward rounds-what content can be leveraged for learning and teaching? It was intended that 
the findings may provide a basis to approach this complex learning environment more systematically.

\section{Methods}

Using a hospital-based ethnographic approach (Barrett et al., 2017), over the 3-month period from September to December 2016, we observed 30 consultant-led ward rounds in a general medical department at a tertiary paediatric hospital. Ethics approval was received from the Human Research and Ethics Committee (HREC) at Royal Children's Hospital Melbourne.

Two researchers individually observed and took detailed notes using a predetermined observation tool. The tool drew on educational teaching methodology (Nunan, 1991; Richards \& Renandya, 2002) to document how learning and teaching of trainees or students occurred, specifying, for example, if the activity was teacher- or learnercentric, the communication method used, the types of questioning used and whether the reasoning was made explicit. To document educational content, the CanMEDS framework (a widely recognised framework which defines competencies required for effective medical practice) was used (Appendix).

One researcher was a paediatrician who worked in general medicine and as a medical educator. The other researcher was an educationalist who had a background in learning and teaching in higher education and teaching clinical communication skills and had worked at the hospital in medical education for 8 years. The paediatrician had the role of an "insider" and the educationalist as an "outsider" in the context of medical ward rounds, both having advantages for the purpose of this research (West et al., 2013).

The observation tool was complemented by key informant interviews (USAID, 1996) of medical teams during and after observed rounds, and with individual consultants following observed rounds. The hospital had approximately 350 beds, and general medical patients were admitted predominantly to two wards comprising 54 beds in total. Consultant-led ward rounds took place predominantly in the morning and usually comprised four consultant-led teams rounding at one time. We observed 12 different consultants, ranging from first-year consultants to those with decades of experience, during a total of 30 different ward rounds. Each researcher accompanied one consultant and their team for the duration of the morning round. The ward rounds usually commenced at $9 \mathrm{am}$ and were completed by approximately $12 \mathrm{pm}$. The number of patients seen varied between five and 24 patients on a round, but most commonly 10 to 15 . Teaching activity varied according to how busy the treating team were. On average, each patient visit took approximately 10 minutes, with additional discussions between consultants, trainees and students outside the room and in corridors between patients. All of these consultant-student discussions were observed and documented along with the key informant interviews.

Completed observational tools, field notes and interview data were de-identified. For the purpose of this paper, we examined the data through the lens of Argyris and Schön's (1974) theory of action, which includes "espoused theory" and "theoriesin-use". Espoused theory identifies what individuals claim to follow, in this instance 
CanMEDS. That which can be inferred from observing actual practice (e.g., education on ward rounds) is theory in use (Argyris et al., 1985).

Directed qualitative content analysis (Hsieh \& Shannon, 2018) of data was performed to identify the educational content that was taught or observable on rounds, using CanMEDS domains as a guide for initial codes. CanMEDS was selected as a globally recognised framework, which currently underpins the hospital medical education and national physician college training curricula. The two researchers identified codes independently and then compared to reach agreement on the key themes-both in terms of their content, but also in terms of which "espoused' themes were explicitly in use. Our findings, reported here, were fed back to the participants in departmental and hospital meetings to ensure they were perceived as accurate from the participant perspective.

\section{Results}

Some general findings emerged describing the nature of learning and teaching on ward rounds. Overwhelmingly, education was impromptu and unplanned, with content guided by the patient's presenting illness. Education was delivered in a largely implicit way and often embedded in the tasks required for patient care rather than overtly identified by the bedside in front of patients and families. At times, case-based discussions were explored further in the corridor outside the room, where consultants asked trainees and medical students questions to apply and extend the learning at the bedside. Clinical content (the technical knowledge of medicine) was clearly prioritised by consultants, although much educational opportunity emerged in other domains, such as communication, professionalism and teamwork. However, these learning opportunities were rarely explicitly harnessed or explicitly reflected on by the team in the form of educational discussions after the round.

Figure 1 represents the themes that emerged from the data as layers of learning potential in ward rounds. Central to both practice and learning is the patient and the core clinical content relating to their presentation. Beyond this is the broader but critical skill of communication, followed by other professional skills and formation of professional identity. These all take place within an institutional cultural context, which impacts on how we learn and teach. Each layer is discussed below.

\section{The first layer-clinical learning}

Clinical learning generally included education around clinical decision making, diagnosis, medical treatment and clinical management of the patient. Opportunities for clinical learning in this setting appeared frequently and were generally prioritised by the consultant as the focus of learning. There were many examples of the consultant questioning students and trainees around clinical knowledge.

What else should be in our differential? Can we exclude a urinary tract infection from a dipstick? What do you make of the story?" (Consultant 1 to junior doctor)

There was frequent referral to patient charts, $\mathrm{x}$-rays, laboratory tests and interpretation and discussion regarding how these relate to the management plan of the patients. 


\section{UNPACKING THE LEARNING ON CONSULTANT-LED WARD ROUNDS}

\section{Figure 1}

The Layers of Complexity of Ward Round Learning and Teaching Content as Drawn From the Study Data

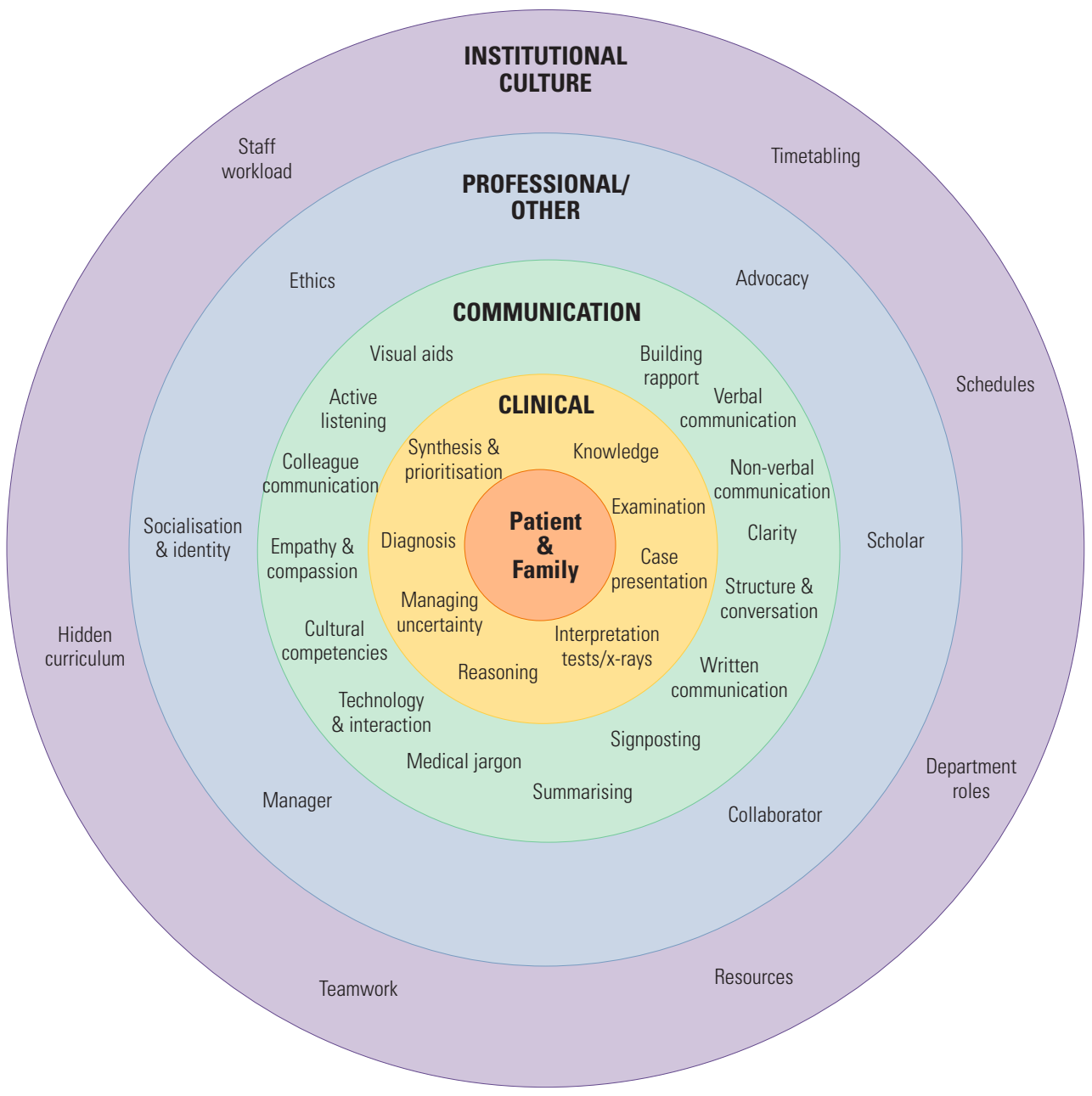


There were also frequent examples of clinical reasoning, both of consultants thinking aloud or talking through their decision-making process and asking trainees to reflect on their own clinical reasoning of what was occurring with the patient.

Just to summarise my thinking: 1) the patient is not too unwell, 2) this is probably a virus and 3) this is what I think we should do. (Consultant 2 to medical team)

Consultants often modelled clinical examination of patients, and sometimes trainees were encouraged to examine and report back to the consultant as an active learning exercise.

His tummy is really soft —I'm happy with that. (Junior resident to consultant 3)

Diagnosis was generally discussed within the team, with the consultant either determining the diagnosis or explicitly asking the team to come up with a diagnosis. This often occurred in the corridor before or after a patient interaction, particularly if there was uncertainty or sensitive diagnoses involved.

There were examples of synthesising facts, either through case presentations or by summarising information and management plans for patients and families. Dealing with clinical uncertainty also featured prominently. Clinical management of the child and prioritisation of a mode of treatment were a focus of educational modelling and were largely driven by the consultant. At times though, consultants asked their trainees for a management approach.

\section{If you were the boss, what would you do? (Consultant 5 to registrar)}

\section{The second layer-communication}

Communication involved all verbal and non-verbal spoken communication in direct interactions and written communication between staff. Vast amounts of complex communication between patients, families and the treating team were observed; however, the focus of this section is on communication with patients and families. There were examples of positive modelling of communication, but this remained implicit from an education perspective. Consultants tended to ignore the features of communication, how they communicated or why patients and families reacted to the communication in the way that they did.

\section{Verbal communication}

Examples of effective verbal communication included explicit introductions of the medical team and their role to the patients and families, clear synthesised explanations of complex conditions and well-structured conversation that incorporated signposting parts of the interaction to aid understanding for patients and families.

So there are three things we need to focus on 1) ... 2)... (Consultant 2 to mother) There were examples of "chunking and checking" to break up large amounts of conversation into understandable chunks of language and then check understanding before moving on to the next part of the discussion. There were examples of doctors seeking clarification. 
When you say "wet in the chest", what do you mean? (Consultant 6 to mother)

Furthermore, skills in using age-specific language for paediatric patients of different ages and skills in clarifying complex discussions for both children and parents were also evident. Moreover, use of feedback strategies such as "uhuh", "yep" and "mmm" also demonstrated active listening and engagement.

Conversely, there were many examples of obtuse language, medical jargon and terminology and unwieldy, complex and unstructured discussions that were not summarised or explained, which appeared to cause confusion for parents.

\section{Non-verbal communication}

Non-verbal communication was a feature of all interactions between parents, children and the treating team. In particular, non-verbal signs appeared to be especially visible when parents or children were stressed, anxious or uncomfortable. Specifically, eye contact, listening skills, gestures and body positioning, facial expressions and head movements, such as nodding, were all relevant and key to communicating emotion, engagement and interest. These were rarely discussed with the trainees and students or the focus of explicit education.

\section{Other aspects of communication}

Building rapport was constantly modelled at the bedside. Some doctors demonstrated how to engage children and families from the outset of introductions to the final words when leaving the room.

You'll see many people today. It can be confusing-just ask them who they are. I'm sure other questions will come up. Just jot them down and we can touch base later. (Consultant 6 to anxious teenage boy)

Clear displays of empathy and compassion were demonstrated through the use of explicit empathy statements. For example, this interaction with a tearful mother awaiting results.

It may take a while to know for sure, and that's really annoying. We're used to that, but it's a lot harder for you. (Consultant 7 to mother)

There was great complexity in dealing with multiple conversations in the roomchildren and parents at the same time, colleague-to-colleague conversations and information sharing, such as examination results, and checking on notes and test results via the electronic medical record (EMR) computer present in the room.

Awareness of cultural background featured when consultants interacted with families of culturally and linguistically diverse backgrounds. Clear language, the use of visual aids and the use of interpreters was modelled with a three-way exchange of information. At times, consultants also modelled interest in the opinions of the family.

So, you think every day that he's clinically getting better? In your experience, have you observed him getting better at each admission? (Consultant 7 to mother) 
However, whilst there were vast amounts of modelling around communication, this was rarely explicitly addressed with trainees or students in discussion outside the room in order to harness its learning potential. Furthermore, feedback was rarely sought or given to trainees regarding their own communication with patients and families.

\section{The third layer-professional skills and identity}

During service delivery, professional skills, identity and cultural socialisation were constantly observed, yet again rarely alluded to explicitly. However, the provision of service forced professional issues to emerge, such as advocating for a child, ethical decision making, multidisciplinary collaboration and teamwork, and were a feature of good care. Many of the professional skills we saw demonstrated components of the CanMEDS framework, e.g., manager, collaborator, health advocate and scholar.

\section{Manager}

Whilst consultants modelled patient and team management, junior trainees practised their own management skills in the role of completing tasks and activities, ordering tests and medications, summarising case presentations and preparing discharge summaries. They had to prioritise and juggle competing demands.

\section{Collaborator}

Teamwork was evident at every moment. This was apparent through the relationships within the team, and the division of roles and responsibilities, but also the intricacies of colleague communication with nursing staff, allied health professionals and subspecialty colleagues. There were many examples of respectful acknowledgement of interdisciplinary team members to patients and families to demonstrate continuity of care and quality teamwork. Furthermore, including parents and patients as part of the decision making was apparent.

We've spoken to all the teams, and we have discussed and think we need to help you with nausea, mood and energy level. Which is the priority for you? (Consultant 7 to teenage patient)

\section{Health advocate}

Subtle advocacy was present in doctors' management of their individual patients and efforts to provide the best care, resources and support for them. This was most explicitly done through the process of consultation or imaging requests, when consultants specifically highlighted the acuity of the patient's need for the service requested and how hard the team should push for a response.

\section{Scholar}

Much discussion of evidence-based care was used, with clinical practice guidelines, evidence from the literature and hospital-based research frequently mentioned. For example:

So what do you know on the literature on tongue tie? (Consultant 8 to junior doctor) 


\section{Socialisation and identity}

Clear roles, responsibilities and positions in a community of practice were also evident. The most junior doctor tended to be "attached" to the computer, documenting rounds in the EMR, while the more senior trainees took on increasing responsibility in the management of tasks and activities. Consultants often led the team into the room with the trainees following behind. A subtle hierarchy could be detected by the observers based on these actions.

\section{The fourth layer-institutional cultural context}

Doctors were observed to deal with complex departmental operational systems, subtle hierarchy and time constraints. They worked within systems where test results, laboratory reports and specialist input all took time and impacted on workflow. Furthermore, the new EMR system added another dimension of complexity and was at times onerous, as staff took time to manage the flow of data within this system. Interestingly, peer-to-peer colleague teaching was an observed consequence, as different doctors were required to access the EMR and had varying degrees of experience and skill with this new technology.

Such institutional factors impacted on every aspect of work yet were rarely explicitly addressed in education as impacting on professional skills, management or communication with colleagues. Discussion of management skills, dealing with uncertainty, prioritising tasks given the hospital structures and communication across departments were constant occurrences but not identified as an opportunity for professional education. At times, system issues and patient safety education opportunities arose but due to time constraints and priorities were often left unexamined.

\section{Discussion}

This study attempted to understand the "theory in use" (Argyris et al., 1985) by doctors in regards to their learning and teaching on ward rounds. Clearly, ward round learning and teaching offers an array of educational possibilities and has been identified as a valuable method of teaching (Dent \& Harden, 2009). It offers the opportunity to blend the authenticity of patient care with professional practice (Ker et al., 2008).

When deconstructing the layers of learning, a complex picture of learning potential emerged. Learning potential seemed to be divided into a number of areas. Learning included tasks necessary for one to do their job, including ordering tests, prescribing antibiotics, consulting a subspecialty colleague and learning clinical content and skills to be a good doctor (for example, clinical knowledge, clinical reasoning and management). Other critical areas of learning included communication, professional skills and acculturation to a department and an organisational system. Furthermore, critical skills of dealing with complexity, unpredictability and uncertainty needed to be interwoven with providing quality, safe and patient-centred care whilst achieving socialisation and identity development. Most of these learning opportunities were, however, implicit and ad hoc. Learning was reactive, responding to the context and environment. 
As an organisation, we espouse that professionalism and the CanMEDS domains of professional, manager, collaborator, health advocate and scholar are prioritised (Frank et al., 2015). These are foregrounded in much training college curricula and in medical education documentation. However, in practice, these domains are rarely explicitly addressed or identified as part of day-to-day ward round learning. There was a clear clinical focus to ward round education, which is understandable given the complexity of decision making facing clinicians (Trimble, 2015). Whilst some may argue that there is an opportunity to explore communication and professionalism in simulated or classroom environments away from the wards, we would argue that the authenticity of the situated learning environment (Lave \& Wenger, 1991) of the ward round is a powerful way to explicitly target these skills through real-time feedback and discussion and emphasise their importance (Billett, 2020).

As no key learning objectives existed within the department that was the focus of this study, most consultants had an informal, intuitive mechanism driving their teaching approach. Therefore, the content to be taught was dependent on the interpretation of the consultant. In many situations, the "theory in use" appeared to be that clinical contentmedical expertise-is prioritised. Education opportunities around professional domains of advocacy, communication, scholar, collaborator and management arose but were largely left implicit. Professional skills are rarely explicitly addressed in formal university examinations, and this may have an unintended consequence of devaluing these domains. They may, therefore, be construed as lesser or softer skills, as they can be seen as a poorly defined and vague educational construct (Mickelson \& MacNeily, 2008). Professionalism is seen in terms of workplace learning (learning to do the job) rather than the critical professional domains identified by CanMEDS. There is huge opportunity on ward rounds to reinforce professional skills training (often taught more formally) and reflect on these in practice.

Communication, a critical aspect of safe patient care, needs to be addressed explicitly as a focus for education (Silverman et al., 2013). The role of patients as potential providers of feedback is another important area of education that can be explored (Toubassi et al., 2018). Often, professional skills development and identity framing were occurring during ward rounds but were not harnessed to help acculturate doctors into a community of practice (Lave \& Wenger, 1991).

Addressing the dissonance between the theory we espouse and that which exists in action requires both awareness of this gap and strategies for changing how we learn and teach in this setting. An evidence-based, structured or planned approach (Ker et al., 2008) could make more of the potential that exists. This would ideally address the implicit nature of learning (Swanwick, 2014), set the agenda of learners (Gray \& Enright, 2018) and encourage reflection (Fish \& Coles, 2005), active learning (Melo Prado et al., 2011; Merritt et al., 2018) and effective feedback (Swanwick, 2014). A more structured approach, together with training in learner-centred approaches, could also support teachers to teach more effectively (Gray \& Enright, 2018).

This paper deliberately prioritised identifying the "what" of the content on ward rounds and found that many learning opportunities were not realised. The potential for broad 
learning in the ward round context is clear, but the participants in this study may not have been fully aware of this potential. This possibility is supported by the fact that much of the data relating to the potential for learning in a range of content areas emerged from observation rather than informant interviews. Perhaps the complexity of ward rounds as well as assumptions that are predominant in rounds, such as the focus on learning medical expertise (Gray \& Enright, 2018), may make it difficult for participants in the round to appreciate the full educational potential.

\section{Limitations}

This study had some limitations. Firstly, the presence of observers may have impacted the quality and quantity of teaching taking place on the ward rounds. In addition, the study presents observation of one department within one hospital, and this may not necessarily be generalisable. There also may be inconsistency in what is viewed and subjective interpretation of what we see; however, the use of two researchers of different backgrounds to observe, analyse and compare themes from data in this study provided an opportunity to increase the trustworthiness of the findings alongside the triangulation of data from different sources. Furthermore, as this is a complex multitasking environment, there may be times when interactions were missed, as the observers stayed with the consultant and may have failed to see other learning opportunities occurring elsewhere, for example, in conversations later in the day or during post-ward round coffee.

Future research might involve comparison across departments, specialty environments, alternative work-based learning environments, such as outpatient departments, or among other health professions where similar issues may exist. Understanding the perceptions of clinicians, both learners and teachers, regarding priorities for education in different contexts is also needed. Furthermore, the role of patients and families as educational partners warrants further exploration. Strategies to support the quality of learning and teaching and to embed or emphasise explicit teaching of broader skills such as communication in clinical contexts need to be researched to understand how we can best utilise these opportunities in busy clinical contexts.

\section{Conclusion}

Ward round education is understandably complex. Competing demands exist between service provision and education, and doctors are constantly under intense pressure to manage a large number of patients competently and safely. There is great potential for learning on ward rounds, yet consultants mostly prioritise clinical content. Professional domains deserve more explicit attention, as does the pedagogical approach of our consultant educators. This shift in thinking requires us to use educational theory and a structured approach to enable a move away from historical models. What is clear is that we need to educate our future clinicians to provide the most clinically competent, professional and safe care for our patients and families. Understanding, and better exploiting, the potential opportunities for learning that occur on busy ward rounds might just be one important step along the way. 


\section{Funding and conflict of interest statement}

No conflict of interest exists. All authors have contributed to the paper and all authors are accountable for the accuracy and integrity of all aspects of the reported work. All authors agree to the copyright conditions. Funding was provided by the Royal Children's Hospital Foundation.

\section{References}

Argyris, C., Putnam, R., \& Smith, D. M. (1985). Action science. Jossey-Bass. Argyris, C., \& Schön, D. A. (1974). Theory in practice: Increasing professional effectiveness (1st ed.). Jossey-Bass.

Barrett, J., Trumble, S. C., \& McColl, G. (2017). Novice students navigating the clinical environment in an early medical clerkship. Medical Education, 51(10), 1014-1024. https://doi.org/10.1111/medu.13357

Billett, S. (2020). Learning in the workplace: Strategies for effective practice. Allen \& Unwin.

Dent, J. A., \& Harden, R. M. (2009). A practical guide for medical teachers (3rd ed.). Elsevier Churchill Livingstone.

Dewhurst, G. (2010). Time for change: Teaching and learning on busy post-take ward rounds. Clinical Medicine, 10(3), 231-234. https://doi.org/10.7861/ clinmedicine.10-3-231

Fish, D., \& Coles, C. (2005). Medical education: Developing a curriculum for practice. Open University Press.

Frank, J. R., Snell, L., \& Sherbino, J. (Eds.). (2015). CanMEDS 2015 physician competency framework. Royal College of Physicians and Surgeons of Canada.

Gray, A., \& Enright, H. (2018). Opening the black box: An observational study of teaching and learning interactions for paediatrics trainees on consultant ward rounds. Journal of Paediatrics and Child Health, 54(9), 1011-1015. https://doi. org/10.1111/jpc. 14056

Hsieh, H. F., \& Shannon, S. E. (2005). Three approaches to qualitative content analysis. Qualitative Health Research, 15(9), 1277-1288. https://doi. org/10.1199/1049732305276687

Ker, J., Cantillon, P., \& Ambrose, L. (2008). Teaching on a ward round. BMJ, 337, Article 1930. https://doi.org/10.1136/bmj.a1930

Laskaratos, F. M., Parry, D., \& El-Mileik, H. (2016). The educational value of posttake ward rounds for senior trainees. Ulster Medical Journal, 85(2), 113-117. https://discovery.ucl.ac.uk/id/eprint/10078763/

Laskaratos, F. M., Wallace, D., Gkotsi, D., Burns, A., \& Epstein, O. (2015). The educational value of ward rounds for junior trainees. Medical Education Online, 20, Article 27559. https://doi.org/10.3402/meo.v20.27559

Lave, J., \& Wenger, E. (1991). Situated learning: Legitimate peripheral participation. Cambridge University Press. 
Melo Prado, H., Hannois Falbo, G., Rodrigues Falbo, A., \& Natal Figueirôa, J. (2011). Active learning on the ward: Outcomes from a comparative trial with traditional methods. Medical Education,45(3), 273-279. https://doi.org/10.1111/ j.1365-2923.2010.03846.x

Merritt, C., Munzer, B. W., Wolff, M., \& Santen, S. A. (2018). Not another bedside lecture: Active learning techniques for clinical instruction. AEM Education and Training, 2(1), 48-50. https://doi.org/10.1002/aet2.10069

Mickelson, J. J., \& MacNeily, A. E. (2008). Translational education: Tools for implementing the CanMEDS competencies in Canadian urology residency training. CUAJ, 2(4), 395-404. https://doi.org/10.5489/cuaj.838

Nunan, D. (1991). Language teaching methodology: A textbook for teachers. Prentice Hall.

O'Hare, J. A. (2008). Anatomy of the ward round. European Journal of Internal Medicine, 19(5), 309-313. https://doi.org/10.1016/j.ejim.2007.09.016

Patton M. (2011). Developmental evaluation: Applying complexity concepts to enhance innovation use. The Guildford Press.

Powell, N., Bruce, C. G., \& Redfern, O. (2015). Teaching a "good" ward round. Clinical Medicine, 15(2), 135-138. https://doi.org/10.7861/ clinmedicine.15-2-135

Richards, J., \& Renandya, W. A. (2002). Methodology in language teaching: An anthology of current practice. Cambridge University Press.

Silverman, J., Kurtz, S. M., \& Draper, J. (2013). Skills for communicating with patients. Radcliffe.

Stanley, P. (1998). Structuring ward rounds for learning: Can opportunities be created? Medical Education, 32(3), 239-243. https://doi.org/10.1046/j.13652923.1998.00201.x

Swanwick, T. (2014). Understanding medical education: Evidence, theory, and practice (2nd ed.). Wiley Blackwell.

Toubassi, D., Singwi, A., \& Waters, I. (2018). Implementation of a patient-based feedback tool to assess the CanMEDS-FM communicator role. Canadian Family Physician, 64(10), 778-779. https://www.ncbi.nlm.nih.gov/pmc/articles/ PMC6184951/

USAID Center for Development Information and Evaluation (USAID). (1996). Performance monitoring and evaluation tips. https://pdf.usaid.gov/pdf_docs/ PNABS541.pdf

Trimble, M. (2015). The thinking doctor's ward round. Ulster Medical Journal, 84(1), 3-7. https://www.ncbi.nlm.nih.gov/pmc/articles/PMC4330798/

West, C., Stewart, L., Foster, K., \& Usher, K. (2013). Accidental insider: Living the PhD study. Collegian, 20(1), 61-65. https://doi.org/10.1016/j. colegn.2012.03.005 
Date Unit

Consultant Team

\begin{tabular}{|c|c|c|c|c|c|}
\hline $\begin{array}{l}\text { Educational } \\
\text { approach }\end{array}$ & Overall structure & $\begin{array}{l}\text { Teaching } \\
\text { methodology }\end{array}$ & Content & Group dynamics & Comments \\
\hline \multirow[t]{2}{*}{$\begin{array}{l}\text { Examples } \\
\text { - Learner-centered, } \\
\text { didactic, facilitator } \\
\text { as expert }\end{array}$} & $\begin{array}{l}\text { Examples } \\
\text { - Method, e.g.,. } \\
\text { "paper round", } \\
\text { bedside, phone } \\
\text { - Balance of service } \\
\text { and education } \\
\text { - Post-round } \\
\text { activities }\end{array}$ & $\begin{array}{l}\text { Examples } \\
\text { - Modelling } \\
\text { - Ouestion and } \\
\text { answer } \\
\text { - Lecturing } \\
\text { - Observation and } \\
\text { feedback } \\
\text { - Implicit vs explicit }\end{array}$ & $\begin{array}{l}\text { Examples } \\
\text { - Clinical knowledge } \\
\text { - Professionalism } \\
\text { - Communication } \\
\text { - Ethical practice } \\
\text { - Implicit vs explicit }\end{array}$ & $\begin{array}{l}\text { Examples } \\
\text { - Roles on round } \\
\text { - Encouragement of } \\
\text { questioning } \\
\text { - Engagement of } \\
\text { families }\end{array}$ & \\
\hline & $\begin{array}{l}\text { Duration } \\
\text { Time started: } \\
\text { Time ended: } \\
\text { Patient numbers } \\
\text { No. direct contact: } \\
\text { No. discussed only: }\end{array}$ & & & & \\
\hline
\end{tabular}

